\title{
Genome-wide linkage analysis and mutation analysis of hereditary congenital blepharoptosis in a Japanese family
}

\author{
Mitsuko Nakashima $\cdot$ Motoi Nakano $\cdot$ Akiyoshi Hirano $\cdot$ \\ Tatsuya Kishino $\cdot$ Shinji Kondoh $\cdot$ Nobutomo Miwa \\ Norio Niikawa $\cdot$ Koh-ichiro Yoshiura
}

Received: 7 September 2007 / Accepted: 14 October 2007 / Published online: 7 November 2007

(C) The Japan Society of Human Genetics and Springer 2007

\begin{abstract}
Hereditary congenital ptosis (PTOS) is defined as drooping of the upper eyelid without any other accompanying symptoms and distinguished from syndromic blepharoptosis. Two previous linkage analyses assigned a PTOS locus (PTOS1) to 1p32-p34.1 and another (PTOS2) to Xq24-q27.1. In addition, in a sporadic case with a balanced chromosomal translocation $\mathrm{t}(1 ; 8)(\mathrm{p} 34.3 ; \mathrm{q} 21.12)$, the ZFHX4 (zinc finger homeodomain 4) gene was found to be disrupted at the 8q21.12 breakpoint, but there was no gene at the 1p34.3 breakpoint, suggesting the existence of the third PTOS locus (PTOS1) at 8q21.12. We carried out a genome-wide linkage analysis in a Japanese PTOS family
\end{abstract}

M. Nakashima $\cdot$ N. Miwa $\cdot$ K.-i. Yoshiura $(\bowtie)$

Department of Human Genetics,

Nagasaki University Graduate School of Biomedical Sciences,

Sakamoto 1-12-4, Nagasaki 852-8523, Japan

e-mail: kyoshi@nagasaki-u.ac.jp

M. Nakashima $\cdot$ M. Nakano $\cdot$ A. Hirano

Division of Plastic and Reconstructive Surgery,

Nagasaki University Graduate School of Biomedical Sciences,

Nagasaki, Japan

T. Kishino $\cdot$ S. Kondoh

Division of Functional Genomics,

Center for Frontier Life Sciences,

Nagasaki University, Nagasaki, Japan

N. Niikawa

The Research Institute of Personalized Health Sciences,

Health Sciences University of Hokkaido, Hokkaido, Japan

T. Kishino $\cdot$ S. Kondoh $\cdot$ N. Miwa $\cdot$ N. Niikawa

K.-i. Yoshiura

Solution Oriented Research for Science and Technology

(SORST), Japan Science and Technology Agency (JST),

Tokyo, Japan and calculated two-point and multipoint log of odds (LOD) scores with reduced penetrance. Haplotype analysis gave three candidate disease-responsible regions, i.e., 8q21.11$\mathrm{q} 22.1,12 \mathrm{q} 24.32-\mathrm{q} 24.33$, and 14q21.1-q23.2. Although the family size is too small to define one of them, 8q21.11q22.1 is a likely candidate region, because it contains the previously reported translocation breakpoint above. We thus performed mutation, Southern-blot and methylation analyses of ZFHX4 but could not find any disease-specific change in the family. Nevertheless, our data may support the localization of PTOS1.

Keywords Hereditary $\cdot$ Congenital ptosis $\cdot$ ZFHX4

\section{Introduction}

Blepharoptosis is pathological drooping of the upper eyelid. It is classified into myogenic, neurogenic, aponeurotic, and mechanical ptosis according to the primarily affected lesion. Hereditary congenital ptosis (PTOS) distinguished from other syndromic blepharoptosis involves only the upper eyelid. PTOS is genetically heterogeneous, and two modes of inheritance are known: autosomal dominant PTOS1 (MIM \%178300) and X-linked PTOS2 (MIM \%300245). Autosomal PTOS may be further divided into at least two types. Engle et al. (1997) mapped PTOS1 by linkage analysis to 1p32-p34.1, whereas McMullan et al. (2002) found, by the analysis of a sporadic case of PTOS who had a de novo balanced chromosomal translocation $\mathrm{t}(1 ; 8)(\mathrm{p} 34.3 ; \mathrm{q} 21.12)$, that the $Z F H X 4$ gene at $8 \mathrm{q} 21.12$ was disrupted by the translocation but there was no gene at the $1 \mathrm{p} 34.3$ breakpoint, suggesting the third locus at 8q21.12. McMullan et al. (2000) mapped PTOS2 by linkage analysis to Xq24-q27.1. 
We recently encountered a Japanese family with PTOS in which there are nine affected members in five successive generations. Here we report on a linkage analysis and mutation analysis of a candidate gene, ZFHX4.

\section{Materials and methods}

Family and patients

A Japanese family consisted of at least nine members affected with PTOS in five generations (Fig. 1). The disease in the family was found in both genders and transmitted (male to male transmissions twice) directly through successive generations, indicating that it is autosomal dominant PTOS. A total of 18 members including five affected and 12 nonaffected members and one of their spouses participated. The proposita (V-5, Figs. 1, 2) suffered from congenital ptosis on her right eye and visited Department of Plastic and Reconstructive Surgery, Nagasaki University Hospital, at age 15 years. She had severe ptosis (drooping $>4 \mathrm{~mm}$, levator function $=5 \mathrm{~mm}$ ) without any other ophthalmic disorders and appeared to have overaction of the frontalis muscle. She had undergone a levator muscle shortening surgery for her ptosis. Three patients (III-13, IV-2, and IV-12) suffered from unilateral congenital ptosis, and all had undergone a repair surgery. The other patient (III-5) with bilateral ptosis has received no surgical treatment. None of the five patients had any associated ophthalmic disorders. All were examined by one or two well-trained plastic surgeons. The study protocol was approved by the Committee for the Ethical Issues on Human Genome and Gene Analysis in Nagasaki University.

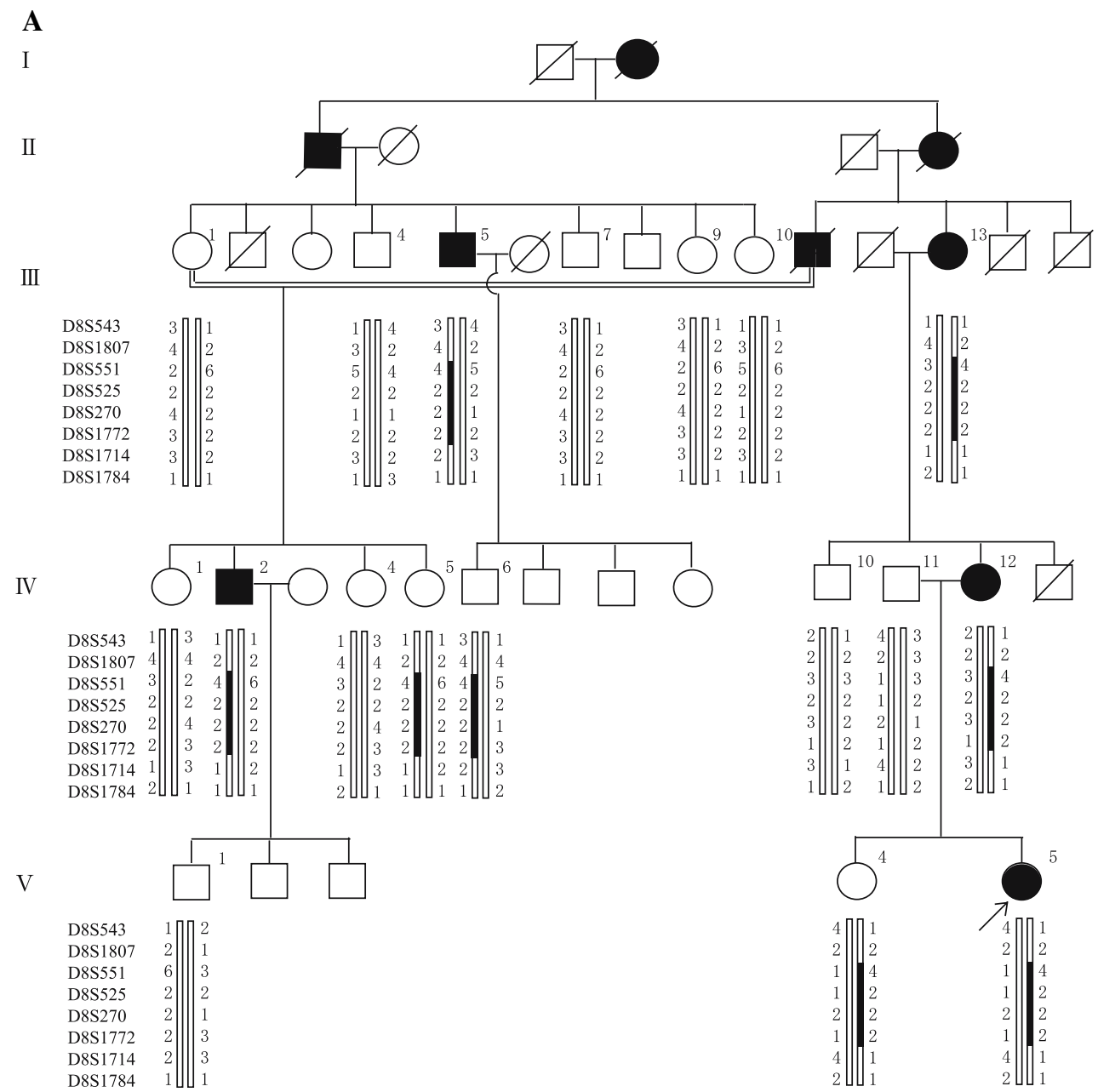

Fig. 1 Family tree with haplotypes at a 8q21.11-q22.2, b 12q24.32qter, and c 14q21.1-q23.2 regions. Closed, open and slash symbols indicate affected, unaffected, and deceased individuals, respectively.
Double horizontal line depicts consanguineous marriage, and short bar above individual symbols indicates individuals examined clinically. Thick columns depict disease-associated haplotypes 


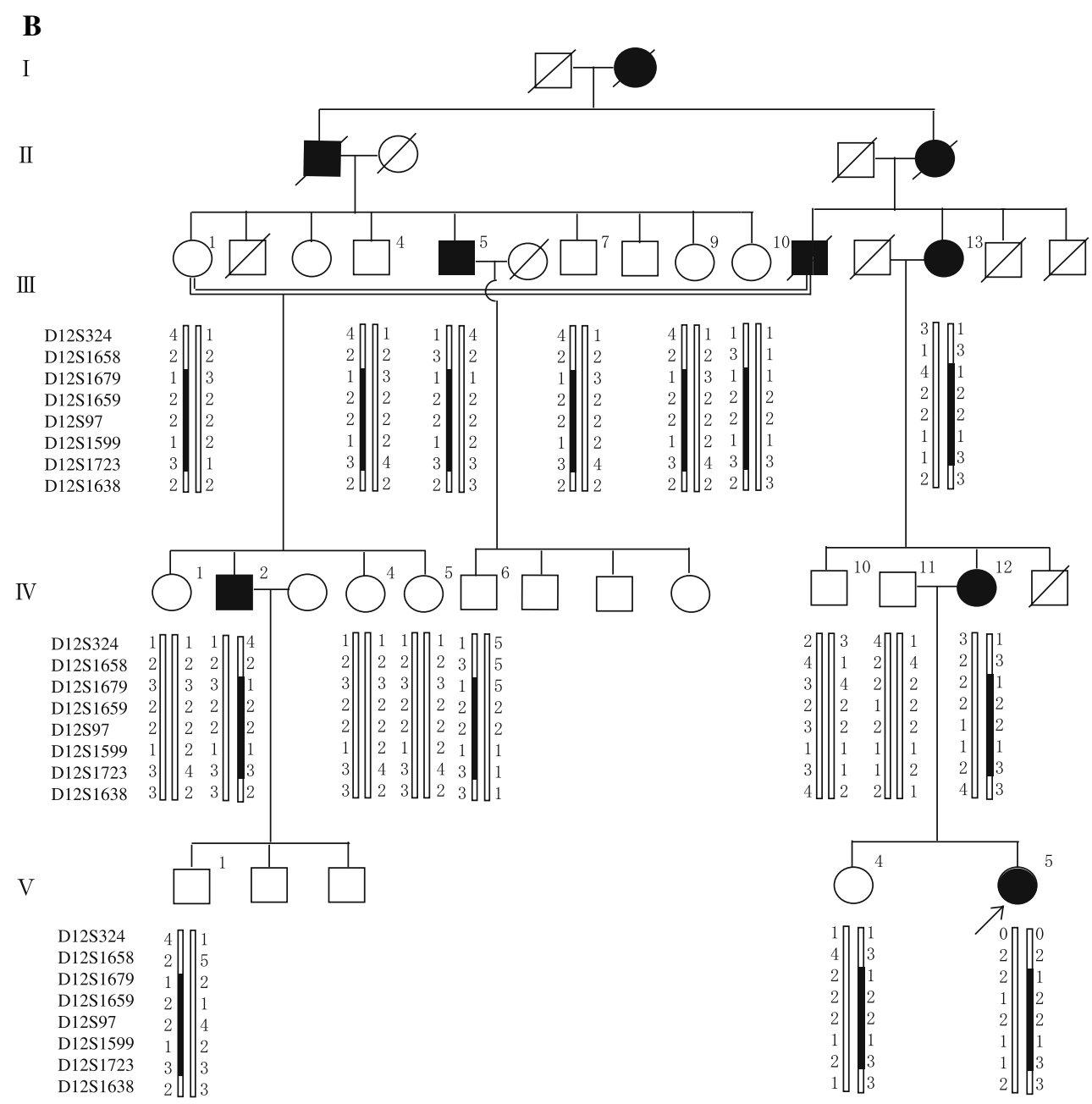

Fig. 1 continued

\section{Linkage and haplotype analyses}

After obtaining written informed consent from each participant, DNA was extracted by conventional method from their whole blood, or using ISOHAIR ${ }^{\mathrm{TM}}$ (Nippon Gene, Tokyo, Japan) from their fingernail clippings, concentrated, and then purified by phenol-chloroform method (Matsuzawa et al. 2006) For whole-genome scanning, we used the ABI Prism Linkage Mapping Set-MD10 (AppliedBiosystems, Foster City, CA, USA) that consists of 386 microsatellite markers from whole chromosomes with average distance of about $10 \mathrm{cM}$. Polymerase chain reaction (PCR) was performed in a $10-\mu$ l mixture containing $5 \mathrm{ng}$ genomic DNA/0.25 U ExTaq DNA polymerase HS-version (TAKARA Bio Inc., Kyoto, Japan) $/ 200 \mu \mathrm{M}$ dNTP/0.3 $\mu \mathrm{M}$ primer/1× PCR buffer on the Dual 384-well GeneAmp PCR System 9700 Thermal Cycler (AppliedBiosystems). The PCR condition was composed of initial denaturation at $94^{\circ} \mathrm{C}$ for $3 \mathrm{~min}$, followed by 37 (blood samples) or 44 (nail samples) cycles of amplification at $94^{\circ} \mathrm{C}, 30 \mathrm{~s} / 55^{\circ} \mathrm{C}, 30 \mathrm{~s} / 72^{\circ} \mathrm{C}, 30 \mathrm{~s}$, and final extension at $72^{\circ} \mathrm{C}$ for $7 \mathrm{~min}$. PCR products were analyzed on an Autosequencer Model 3100. Genotyping was carried out using GeneScan and Genotyper software (AppliedBiosystems).

Two-point $\log$ of odds (LOD) score was calculated using MLINK program (included in FASTLINK software version 4.0P) (Lathrop et al. 1984), and multipoint LOD score and nonparametric LOD score were calculated using Genehunter software (Kruglyal et al. 1996). To pick up all possibly linked loci, calculation was based on an assumption that the ptosis in the family is an autosomal dominant trait with $90 \%$ penetrance $(P=0.9)$ and on the allele frequency of $1 / N$, where the number of alleles is $N$. Haplotypes around loci with positive LOD scores were constructed with four or five microsatellite markers that were set up at intervals of 2-3 cM. Information of these microsatellite markers was referred to the National Center for Biotechnology Information (NCBI) database (Map Viewer: Marshfield and/or decode map). 


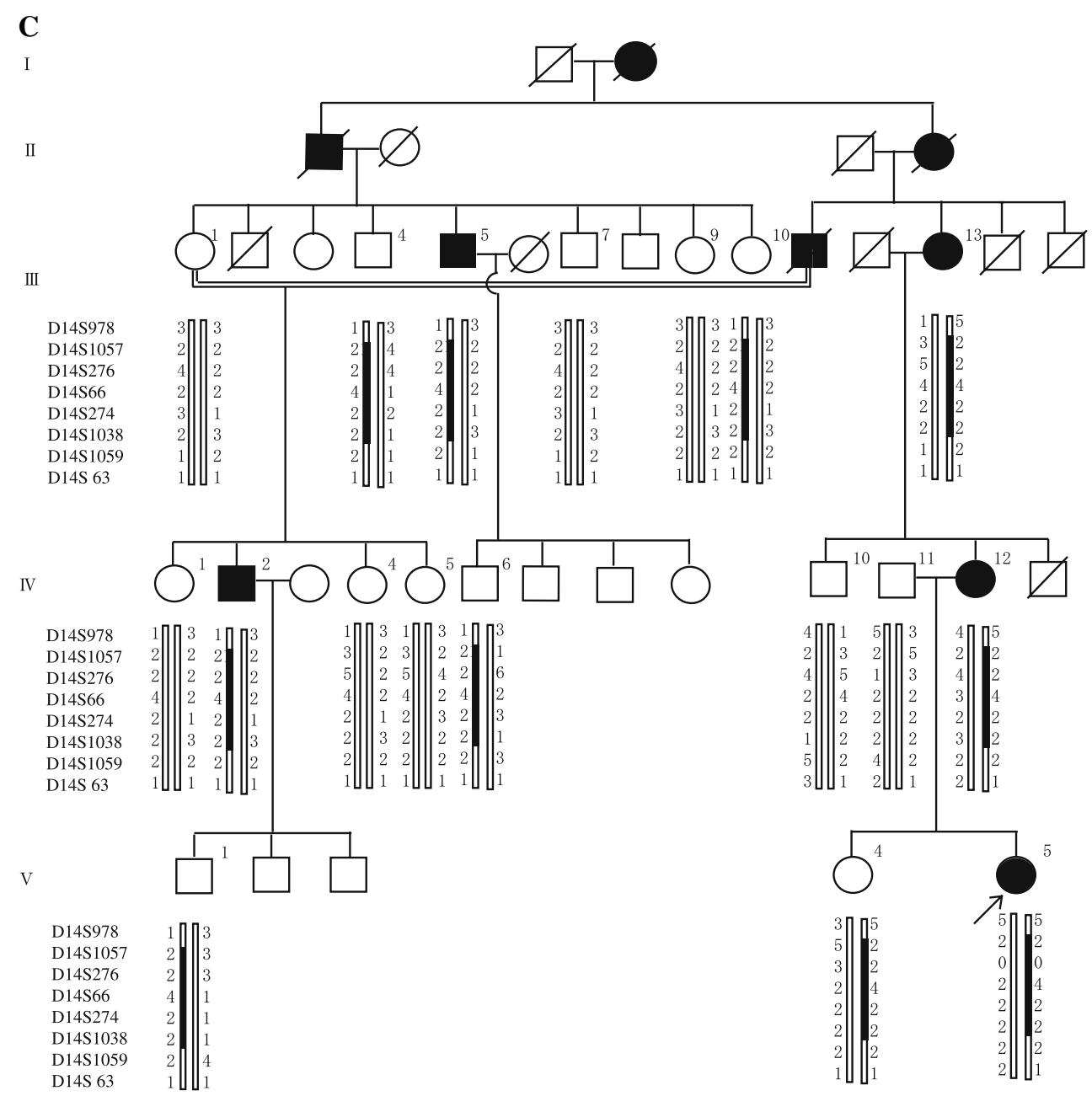

Fig. 1 continued

Mutation analysis

ZFHX4, reported to have been disrupted by a translocation in a patient with PTOS (McMullan et al. 2002), is located at $8 \mathrm{q} 21.1$. As its chromosomal localization is one of candidate regions we identified in the study reported here, we performed direct sequencing of all exons of ZFHX4 using DNA from one affected member (III-5) and one unaffected member (IV-1) in the family. The genomic sequence of ZFHX4 was retrieved from the University of California, Santa Cruz (UCSC) Genome Browser Home (http:// genome.ucsc.edu/) and from the Ensemble Genome Browser (http://ensembl.org/index.html). Primers were designed from sequences of each exon and those around the respective intron. PCR was performed in a $15-\mu 1$ reaction mixture containing $5 \mathrm{ng}$ DNA/0.4 U ExTaq DNA polymerase $/ 200 \mu \mathrm{M} \mathrm{dNTP} / 0.67 \mu \mathrm{M}$ each primer/ $1 \times \mathrm{PCR}$ buffer on DNA Thermal Cycler Model 9700 (AppliedBiosystems) with a condition of initial denaturation at $94^{\circ} \mathrm{C}$ for $3 \mathrm{~min}$, amplification for 37 cycles at $94^{\circ} \mathrm{C}, 30 \mathrm{~s} / 60^{\circ} \mathrm{C}$, $30 \mathrm{~s} / 72^{\circ} \mathrm{C}, 30-60 \mathrm{~s}$, and final extension at $72^{\circ} \mathrm{C}$ for $7 \mathrm{~min}$. PCR products were subjected to cleaning up using Exonuclease I (Epicentre, WI, USA) and shrimp alkaline phosphatase (AmershamBioscience, NJ, USA) for direct sequence reaction. Direct sequencing was carried out using BigDye-terminator sequencing reagent version-3.1 (AppliedBiosystems) on an Autosequencer Model 3100, and sequences were aligned with ATGC software (GENETYX Corp., Tokyo, Japan).

Southern-blot analysis

Genomic DNA from a patient (III-5) as a representative from the family was digested with three different enzymes (BamHI, EcoRI, HindIII) and electrophoresed on $0.8 \%$ agarose gel in $0.5 \times$ TBE buffer containing $0.25 \mu \mathrm{g} / \mathrm{ml}$ ethidium bromide at $35-40 \mathrm{~V}$ for $6-10 \mathrm{~h}$. DNA was then 
denatured with $0.4 \mathrm{~N} \mathrm{NaOH}$ for 15-20 min and capillarytransferred overnight onto nylon membrane (HybondN+, AmershamPharmacia Biotech, Buckinghamshire, UK) using alkaline transfer buffer, and the membrane was washed twice with $2 \times$ SSC. DNA fixed to the membrane by UV crosslinking was hybridized to fluorescein-labeled probes using Gene Images Random Prime Labeling Kit (AmershamBiosciences). Hybridized signal was detected using Gene Image CDP-Star Detection Kit (AmershamBiosciences). Genomic DNA from phenotypically normal individuals were used as controls.
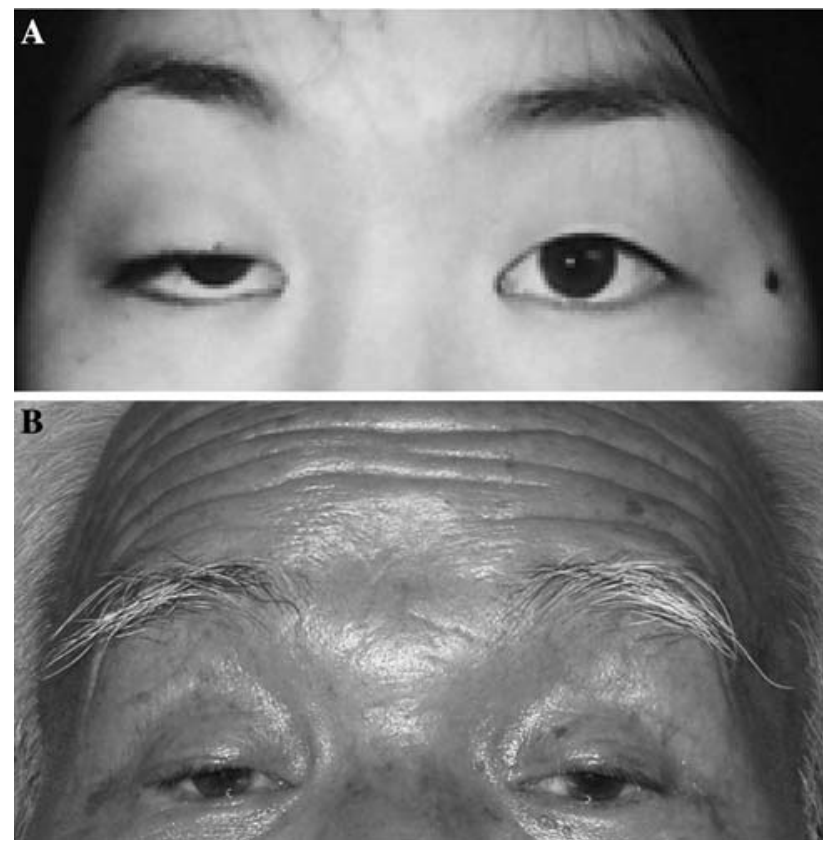

Fig. 2 Blepharopotosis of two affected members (V-5 and III-5). The proband (V-5) has unilateral blepharoptosis (a), and III-5 has bilateral ptosis (b). Both patients have overaction of the frontalis muscle
Methylation analysis of ZFHX4

DNA $(1 \mu \mathrm{g})$ from patients and a control individual was modified with sodium bisulfite using CpGenome DNA modification Kit (CHEMICON, CA, USA). PCR primers specific for methylated or unmethylated DNA (Herman et al. 1996) were designed from sequences of two $\mathrm{CpG}$ islands of ZFHX4 (Table 1), at which one island is located $3 \mathrm{~kb}$ upstream and the other $0.4 \mathrm{~kb}$ downstream of exon 1 , respectively (Hemmi et al. 2006). Methylation-specific PCR was performed in a $20-\mu 1$ reaction mixture containing $50 \mathrm{ng}$ bisulfite-modified DNA/0.5 U AmpliTaq Gold (AppliedBiosystems)/200 $\mu \mathrm{M} \mathrm{dNTP} / 0.5 \mu \mathrm{M}$ each primer/ $1 \times$ PCR buffer with a condition consisting of initial denaturation at $95^{\circ} \mathrm{C}$ for $10 \mathrm{~min}, 37$ cycles of amiplification at $94^{\circ} \mathrm{C}, 30 \mathrm{~s} / 60^{\circ} \mathrm{C}, 30 \mathrm{~s} / 72^{\circ} \mathrm{C}, 30 \mathrm{~s}$, and final extension at $72^{\circ} \mathrm{C}$ for $10 \mathrm{~min}$. PCR products were analyzed by electrophoresis on $2.5 \%$ agarose gel. Because aberrant signals on Southern blot were observed, the bisulfitemodified DNA was also amplified with specific primers for the EcoRI site around exon 12 of ZFHX4. PCR products were cloned using TOPO TA cloning Kit (Invitrogen, Carlsbad, CA, USA), and then cloned DNA was sequenced (Clark et al. 1994).

\section{Results}

Linkage and haplotype analyses

As the number of affected members in this family was small and penetrance might be considerably low, we set a cutoff LOD score $\geq 0.4$ in all calculations. The two-point and multipoint analyses gave nine markers (D1S255, D1S484, D5S630, D7S669, D9S1776, D11S4046, D19S221, D19S226, and D14S276) that show such scores,
Table 1 Polymerase chain reaction (PCR) primers for methylation-specific PCR and bisulfite sequencing

$M$ methylated-specific, $U$ unmethylated-specific, $F$ forward primer, $R$ reverse primer, up upstream restriction site, $d w$ downstream restriction site

\begin{tabular}{llll}
\hline Primer & Sequences $5^{\prime} \rightarrow 3^{\prime}$ & $\begin{array}{l}\text { Anneal } \\
\text { temperature }\end{array}$ & $\begin{array}{l}\text { Products } \\
\text { size (bp) }\end{array}$ \\
\hline CpG1-MF & GTTTAGTCGTTCGGATCGCGTTCGT & 60 & 182 \\
CpG1-MR & AACTTAACCTCGAAACGCGCCAACG & & \\
CpG1-UF & GTTAGGTTTAGTTGTTTGGATTGTGTTTGT & 60 & 192 \\
CpG1-UR & TCCAAAACTTAACCTCAAAACACACCAACA & & \\
CpG2-MF & GGGTTTTGTTTTTTTCGCGAGTTTC & 60 & 139 \\
CpG2-MR & TACGAAAAACCAATCATCCCAATCG & & \multirow{2}{*}{149} \\
CpG2-UF & TTTTTGGGTTTTGTTTTTTTGTGAGTTTT & 60 \\
CpG2-UR & ATAAATACAAAAAACCAATCATCCCAATCA & & \\
Ex12-upF & GGAAAGTAAAGAAGTTGTTTTAAAA & 56 \\
Ex12-upR & ATAACAAAACAATACAACACAAATA & & \\
Ex12-dwF & TGATAATGGTAGAAGGTAAAGTATT & 56 & 200 \\
Ex12-dwR & AACATATAAAACAAAAAAACCTCTA & & \\
\hline
\end{tabular}


and the nonparametric analysis gave four candidate regions (3q22.1, 8q21.11, 12q24.32, and 20p13). The haplotype analysis at these loci revealed that all but 8q21.1, 12q24.3, and 14q22.3 regions (Fig. 1) were excluded, because some patients do not have putative disease-linked haplotypes (data not shown). Thus, we finally left these three regions commonly shared by the patients as candidates. Further refinement was impossible, because any more family samples were not available.

\section{Mutation analysis of the ZFHX4 gene}

The direct sequencing of ZFHX4 revealed one missense alteration (G12411T or L4137F) in exon 12 in the affected member and some normal control samples (data not shown), indicating that it is actually a single nucleotide polymorphism (SNP). Likewise, another mutation analysis for homologous sequences between the mouse and human in their promotor/enhancer region of ZFHX4/ $Z f h x 4$ revealed no disease-associated mutation in the patient. Southern-blot analysis using a probe for exon 2 or exon 12 of ZFHX4 detected a respective extra EcoRIfragment in a patient (III-5) (Fig. 3) and an extra band for exon 12 in two other patients (III-13 and IV-12).There were no aberrant signals with other restriction enzymes. However, sequence analysis of these regions did not identify any genomic rearrangements and confirmed no restriction fragment length polymorphism (RFLP) around exon 2 or 12. This led us to try to detect the differential methylation status in the regions between patients and normal controls. However, methylation-specific PCR following a bisulfite treatment revealed no change of the methylation status in the patient's two $\mathrm{CpG}$ islands (data not shown).

\section{Discussion}

In this study, we performed linkage and haplotype analyses of a Japanese PTOS pedigree. Consequently, three regions, 8q21.11-q22.2, 12q24.32-qter, and 14q21.1-q23.2, were shown to be candidates. The two-point maximum LOD scores were considerably low, being $1.16,0.47$, and 0.72 at D8S551, D12S1659, and D14S276 (Table 2), respectively, because some unaffected family members also had diseaselinked haplotypes around the markers. It was obvious that the disease in the family shows incomplete penetrance. Although we diagnosed carefully many members of the family at the beginning of this study, we might have overlooked very mildly affected members.

Two regions responsible for autosomal PTOS were reported previously, i.e., 1p34.1-p32 for PTOS1 by linkage analysis (Engle et al. 1997) and 1p34.3/8q21.12 by analysis of a chromosomal translocation (McMullan et al. 2002). Three candidate loci we have detected include the translocation breakpoint 8q21.2 (McMullan et al. 2002) but do not contain 1p34.1-p32 (Engle et al. 1997). Therefore, the disease locus for our family could be associated with PTOS1. However, we failed to identify in our family any point mutation, genomic rearrangement, or methylation aberration involving ZFHX4 that was disrupted at the $8 \mathrm{q} 21.12$ breakpoint of the translocation in a PTOS patient (McMullan et al. 2002).

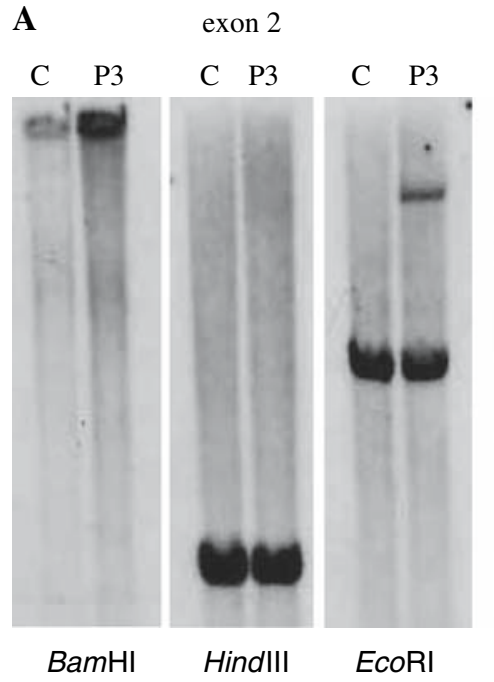

Fig. 3 Southern-blot analysis of patients (P3) and a control individual $(C)$ after digestion with three different enzymes, using probes for exons 2 and 12 of ZFHX4. An extra band is seen in EcoRI fragments,

\section{exon 12}

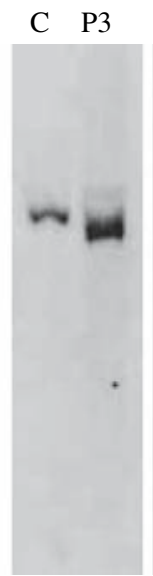

BamHI
C P

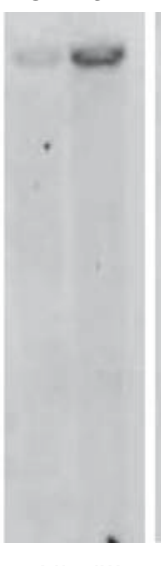

HindIII

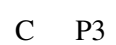

including ZFHX4 from a patient (III-5, P3) (a) and three patients (P1, III-13; P2, IV-12; and P3) (b)
B exon 12

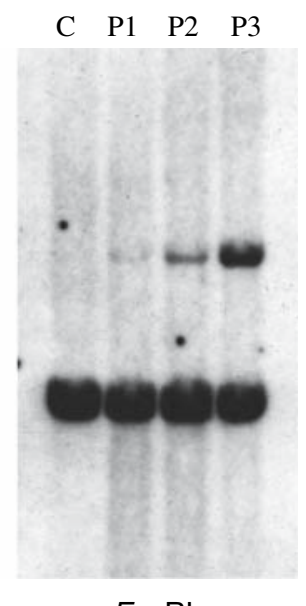

EcoRI 
Table 2 Log of odds (LOD) scores of candidate loci of the third hereditary congenital ptosis locus (PTOS1)

\begin{tabular}{llllllll}
\hline Recombination fraction $(\theta)$ & & & & & Multipoint \\
\hline Locus & 0.00 & 0.05 & 0.10 & 0.20 & 0.30 & 0.40 & LOD score \\
D8S551 & 0.95 & 1.12 & 1.16 & 1.01 & 0.68 & 0.29 & 1.46 \\
D8S525 & 0.15 & 0.12 & 0.09 & 0.05 & 0.02 & 0.00 & 1.51 \\
D8S270 & -2.53 & -1.33 & -0.86 & -0.36 & -0.13 & -0.02 & 1.39 \\
D8S1772 & 0.33 & 0.31 & 0.29 & 0.23 & 0.15 & 0.08 & 1.22 \\
D12S1679 & -0.03 & 0.31 & 0.45 & 0.47 & 0.34 & 0.17 & 0.59 \\
D12S1659 & 0.15 & 0.12 & 0.09 & 0.05 & 0.02 & 0.00 & 1.39 \\
D12S97 & -0.20 & -0.11 & -0.05 & -0.00 & 0.00 & 0.00 & 1.61 \\
D12S1599 & -0.78 & -0.43 & -0.27 & -0.11 & -0.04 & -0.01 & 1.63 \\
D12S1723 & 0.15 & 0.25 & 0.27 & 0.23 & 0.14 & 0.06 & 1.79 \\
D14S1057 & 0.62 & 0.64 & 0.61 & 0.51 & 0.37 & 0.20 & -1.00 \\
D14S276 & 0.46 & 0.65 & 0.72 & 0.65 & 0.44 & 0.19 & 1.31 \\
D14S66 & -1.65 & -1.15 & -0.83 & -0.45 & -0.25 & -0.12 & 2.01 \\
D14S274 & -1.16 & -0.30 & -0.07 & 0.07 & 0.07 & 0.02 & 1.97 \\
D14S1038 & -2.15 & -1.64 & -1.27 & -0.76 & -0.43 & -0.19 & 1.94 \\
\hline
\end{tabular}

The human ZFHX4 gene spans about $180 \mathrm{~kb}$, contains 12 exons, is mapped at 8q13.3-q21.11, and has $>90 \%$ homology to the mouse Zfh4 and 52\% to the human ATBFl (Hemmi et al. 2006). The Zfh4 gene encodes a member of the zinc finger homeodomain family, which has four homeodomains and 22 zinc fingers (Sakata et al. 2000). Zfh4 was highly expressed in developing muscle and brains of the mouse, especially in the midbrain and hindbrain (Kostich and Sanes 1995), and was also detected in adult rat oculomotor nucleus, which controls the levator palpebrae superioris (LPS) muscle (Nogami et al. 2005). The oculomotor nucleus exists in the mesencephalon. The oculomotor nerve innervates to LPS and the extraocular muscles, except for the lateral rectus and the superior oblique muscle, and also supplies parasympathetic preganglionic fibers to the ciliary ganglion through which postganglionic nerve controls the ciliary muscle and the sphincter muscle of the pupil. It was reported that ZFHX4 was upregulated in postmitotic neurons and suggested that ZFHX4 was influenced on neural differentiation including migration and axon outgrowth (Nogami et al. 2005; Hemmi et al. 2006). All these lines of evidence strongly suggest that ZFHX4 is the responsible gene for a type of PTOS.

There are two opinions concerning the pathological change in LPS from congenital ptosis. Three reports approved that congenital ptosis is caused by primary dysgenesis or myodystrophy of LPS (Berke and Wadsworth. 1955; Isaksson and Mellgren 1961; Isaksson 1962; Stula 1988). On the other hand, Edmunds et al. (1998) argued against such a mechanism because there was no significantly different histology between LPS from PTOS patients and normal individuals. A light-microscope study of an LPS specimen from the proband in our family showed that the muscle fibers were displaced by fibrous and fatty tissues, and scanty atrophic striated muscles remained. This histological finding is consistent with dysgenesis of LPS. Therefore, if ZFHX4 is relevant to congenital blepharoptosis, its abnormal expression might cause a failure of neuronal differentiation of the oculomotor nerve, leading to LPS dysgenesis.

In conclusion, we identified three possible regions candidate for PTOS1-8q21.11-q22.2, 12q24.32-qter, and 14q21.1-q23.2-by a whole-genome linkage analysis. These regions do not definitely overlap with a 1p34.1-p32 segment to which PTOS1 was mapped (Engle et al. 1997), and one of the regions we assigned includes a segment containing ZFHX4 (McMullan et al. 2002). Thus, our data may support the existence of the PTOS1 locus. It remains to be seen whether other PTOS1 families have mutations in ZFHX4, another gene, or in a putative ZFHX4 enhancer located at $8 \mathrm{q} 21.11-\mathrm{q} 22.2$.

Acknowledgments We are indebted to the family members for their participation in this study. We especially thank N. Noguchi, A. Goto, and K. Miyazaki for their technical assistance. NN was supported in part by Grant-in-Aid for Scientific Research on Priority Areas (Applied Genomics, No. 17019055) from the Ministry of Education, Culture, Sports, Science and Technology (MEXT) of Japan, and by SORST from the Japan Science and Technology Agency (JST). KY was supported by Grant-in-Aid for Scientific Research on Priority Areas (No. 17590288) from MEXT of Japan.

\section{References}

Berke RN, Wadsworth JAC (1955) Histology of levator muscle in congenital and acquired ptosis. Arch Opthalmol 53:413-428

Clark SJ, Harrison J, Paul CL, Frommer M (1994) High sensitivity mapping of methylated cytosines. Nucleic Acids Res 22:29902997 
Edmunds B, Manners RM, Weller RO, Steart P, Collin JRO (1998) Levator palpebrae superioris fibre size in normals and patients with congenital ptosis. Eye 12:47-50

Engle EC, Castro AE, Macy ME, Knoll JH, Beggs AH (1997) A gene for isolated congenital ptosis maps to a $3 \mathrm{cM}$ region within 1p32-p34.1. Am J Hum Genet 60:1150-1157

Hemmi K, Ma D, Miura Y, Kawaguchi M, Sasahara M, Tamaoki TH, Tamaoki T, Sakata N, Tsuchiya K (2006) A homeodomain-zinc finger protein, ZFHX4, is expressed in neuronal differentiation manner and suppressed in muscle differentiation manner. Biol Pharm Bull 29:1830-1835

Herman JG, Graff JR, Myöhänen S, Kelkin BD, Baylin B (1996) Methylation-specific PCR: a novel PCR assay for methylation status of CpG islands. Proc Natl Acad Sci 93:9821-9826

Isaksson I (1962) Studies on congenital genuine blepharoptosis. Acta Opthalmol 72(Suppl):1-120

Isaksson I, Mellgren J (1961) Pathological-anatomical changes in the levator palpebrae superioris muscle in congenital ptosis. Acta Pathol Microbio Scand 144:157-160

Kostich WA, Sanes JR (1995) Expression of zfh-4, a member of the zinc finger-homeodomain family, in developing brain and muscles. Dev Dyn 202:145-152

Kruglyal L, Daly MJ, Reeve-Daly MP, Lander ES (1996) Parametric and nonparametric linkage analysis: a unified multipoint approach. Am J Hum Genet 58:1347-1363
Lathrop GM, Lalouel JM, Julier C, Ott J (1984) Strategies for multilocus linkage analysis in humans. Proc Natl Acad Sci USA 81:3443-3446

Matsuzawa N, Shimozato K, Natsume N, Niikawa N, Yoshiura K (2006) A novel missense mutation in Van der Woude syndrome: usefulness of fingernail DNA for genetic analysis. J Dent Res 85:1143-1146

McMullan TFW, Collins AR, Tyers AG, Robinson DO (2000) A novel X-linked dominant condition: $\mathrm{X}$-linked congenital isolated ptosis. Am J Hum Genet 66:1455-1460

McMullan TFW, Crolla JA, Gregory SG, Carter NP, Cooper RA, Howell GR, Robinson DO (2002) A candidate gene for congenital bilateral isolated ptosis identified by molecular analysis of a de novo balanced translocation. Hum Genet 110:244-250

Nogami S, Ishii Y, Kawaguchi M, Sakata M, Oya T, Takagawa K, Kanamori M, Sabit H, Obata T, Kimura T, Sasahara M (2005) $\mathrm{ZFH} 4$ protein is expressed in many neurons of developing rat brain. J Comp Neurol 482:33-49

Sakata N, Hemmi K, Kawaguchi M, Miura Y, Noguchi S, Ma D, Sasahara M, Hori M, Tamaoki T (2000) The mouse zfh-4 protein contains four homeodomains and twenty-two zinc fingers. Biochem Biophys Res Commun 273:686-693

Stula FC (1988) Histological changes in congenital and acquired blepharoptosis. Eye 2:179-184 